\title{
The Development of the a World Database of Freshwater Algae-Indicators
}

\author{
Sophia Barinova (Corresponding author) \\ Institute of Evolution, Haifa University, \\ 199 Abba Khoushi Ave., Mount Carmel, Haifa, 3498838, Israel \\ Tel: 972-4-8249-799Ｅ-mail: sophia@evo.haifa.ac.il
}

\begin{abstract}
Tzion Fahima
Institute of Evolution, Haifa University,

199 Abba Khoushi Ave., Mount Carmel, Haifa, 3498838, Israel

Tel: 972-4-8240-784 E-mail: fahima@ research.haifa.ac.il
\end{abstract}

Received: April 13, 2017 Accepted: April 17, 2017 Published: May 15, 2017

doi:10.5296/jee.v8i1.11228ＵRL: https://doi.org/10.5296/jee.v8i1.11228

\begin{abstract}
This paper presents results of a database compilation for indicator species from fresh and brackish aquatic habitats. Information about aquatic species ecology was collected from international guides, our own research during the last 40 years, as well as from monographs and electronic resources describing the ecology of diverse taxonomic groups of organisms. Most of the species represented in the database belong to algae and cyanobacteria taxa, but the ecology of some other aquatic organisms, such as higher plants, moss, and bacteria is also documented. Altogether, 8475 algal, cyanobacteria, plants, and other aquatic inhabitants from 36 taxonomical divisions are represented in the database. Ecological information is given according to 12 indication methods for the following parameters: confinement to the substrate, temperature, oxygen, and the mobility of the water mass, preferences to water $\mathrm{pH}$, water salinity, saprobity according to Watanabe, saprobity according to Sládeček, saprobity index (SI) according to Sládeček, trophic states, nutrition types and several others. This comprehensive database is scheduled for publication in a book and can be used by a wide spectrum of ecologists for the purpose of aquatic ecosystem assessment and monitoring of water quality based on bioindication methods.
\end{abstract}

Keywords: Algae, Ecological preferences, Indicators, Database 


\section{Introduction}

The maintenance of water quality at a high level is of considerable importance. For the most part, the water comes from natural sources including rivers, lakes, and reservoirs. The quality of their water should not only be assessed, but also predicted. Under natural conditions, water quality depends on the river basin and on the ecosystem of the water body. Considering that water quality assessment is rather expensive, elaboration of express-methods of its assessment is an urgent problem.

The bioindication analysis is based on the hierarchical organization of the biotic community, which is described by the model of the trophic pyramid (UNEP/IPCS, 2006). However, in the natural ecosystem relationships, distinguishing between the levels is more complicated (Whitton, 1975). The distribution of the groups of organisms or species over the intervals of environmental factors is also of considerable importance.

Pollution of freshwater aquatic systems is a complicated problem, and therefore relevant assessment methods to determine the ecosystem's structure must be chosen carefully. The methods and indices that can be used for assessment of pollution impact on natural water bodies are based on the ecological character of the water and biota relationships within the system. Aquatic ecosystems of fresh and brackish water bodies are well represented in the Earth's surface.

The relationships between algal biodiversity and environmental conditions are determined by the adaptation level of the species and the community as a whole. Bioindication is based on the principle of congruence between community composition and the complexity of environmental factors. However, defining the role of particular environmental variables as well as to predict the community's response to environmental change is still problematic. Furthermore, summarizing the accumulated information on environmental factors and biota in order to classify the variables and assess the impact of pollution is quite challenging. Here, in the Institute of Evolution, we set out to collect ecological information about aquatic species of algae, cyanobacteria, plants, moss and other water-living organisms for the ecological database compilation. Our work started in 2001 and now we are ready to present the results in a book that will be published during the coming year.

We aimed to summarize known information about ecological preferences of algae, cyanobacteria, and other types of organisms inhabiting fresh and brackish aquatic habitats for the purpose of using it for water quality bioindication.

\section{Material and Methods}

\subsection{Principle Approach}

The bioindication method, based on analyzing the response of biota to changes in environmental conditions, is of great significance in estimating the effect of pollution on aquatic ecosystems. It should be noted that the bio-indication method is reflecting the real changes under natural conditions, in contrast to standard bioassays that are conducted under controlled laboratory conditions. Therefore, the major methods used for the assessment of 
pollution impact can be divided into two different groups: 1) methods of bioindication on the basis of species that were found in the studied natural habitats and 2) methods of bio-testing that were based on the organism's response to the environmental conditions to which it is exposed during laboratory experiment. For the purpose of pollution impact assessment on natural aquatic ecosystems, we present in our study descriptions and results combining both of these methods. Furthermore, in order to be able to determine the water quality or asses the ecosystem state we have collected the relevant ecological data for each of the aquatic species in our database.

\subsection{Collecting Methods and Presentation}

Data on ecological preferences of algal species were taken from more than 120 monographs and published papers. The collected information about each of the species was inserted to an Excel table, and then the data was classified according to categories of bioindication. The ecological characteristics of algal species diversity were used for grouping freshwater organisms according to the following major variables: $\mathrm{pH}$, salinity, temperature, streaming and oxygenation, trophy, nutrition preference, and saprobity, which were obtained from the database in the Microsoft Access Program. Information was compiled from recent references for freshwater algae (Barinova et al., 2006) and more than 150 other sources.

The database was created in 1986 and additional data was added and updated for the purpose of summarizing and using ecological data on freshwater algae for the ecological analysis of aquatic communities and the ecosystem state of diverse aquatic objects of Eurasia. The major principle for ecological data summarization was to find relevant information on the ecology of each taxon. Ecological preferences of each taxon were described in many different references, from which we took all available information and then summarized it for each indicator group. In the integration data process, we made all appropriate and thorough references available in diverse languages and proper publication quality. Therefore, the list of books and papers, from which we have collected and integrated the ecological information, included more than 150 references published from 1951 to the present. The references include not only books, but also electronic resources available in the internet, from which information was taken and revised.

\section{Results}

As a result, the list of bioindicators is based on data integrated from the literature, as well as our own classification of taxa into 12 ecological groups, which are represented by a total of 8475 indicator taxa (Table 1).

Table 1. Number of indicator taxa in the database across ecological groups

\begin{tabular}{|l|l|}
\hline Ecological group of indicators & No. of indicator taxa \\
\hline Habitat preferences & 6308 \\
\hline Temperature & 413 \\
\hline
\end{tabular}




\begin{tabular}{|l|l|}
\hline Rheophility and oxygenation & 1953 \\
\hline Water pH & 2898 \\
\hline pH range & 480 \\
\hline Halobity (Salinity) & 2615 \\
\hline D-Watanabe & 764 \\
\hline Self-purification zone & 5644 \\
\hline Index saprobity S & 5678 \\
\hline Trophy & 2440 \\
\hline Nutrition type (autotrophy-heterotrophy) & 491 \\
\hline H 2 S (sulfides) & 13 \\
\hline Total no. of indicator taxa & 8475 \\
\hline
\end{tabular}

Due to the difficulty of presenting the huge amount of information in one study, data were presented in Microsoft Access databases and a table version, which shows characteristics of bioindicative algae and some other aquatic organisms. The material is based on the references listed for each taxon. In the final version of the table for each indicator taxa data were available from one to 23 sources. If the information contained in various references did not match, we selected data from the most reliable source. First, the most recent information was chosen, second in importance was the information from field observations, third was information from taxonomic summaries, and fourth was the information from references on fossil communities.

The largest taxonomic representations are listed below. Integrated information on the species ecological preferences is presented in our database (Table 2) and included 36 positions. Taxa names are given as in the algaebase.org (Guiry \& Guiry, 2017).

Table 2. Taxonomical presentation of ecological information in our database

\begin{tabular}{|l|l|l|}
\hline No. & Taxa & No. of indicator taxa \\
\hline 1 & Bacillariophyta & 2652 \\
\hline 2 & Charophyta & 1429 \\
\hline 3 & Euglenozoa (Euglenophyta) & 1241 \\
\hline 4 & Chlorophyta & 1127 \\
\hline
\end{tabular}




\begin{tabular}{|l|l|l|}
\hline 5 & Cyanobacteria & 834 \\
\hline 6 & Ochrophyta (Chrysophyta) & 527 \\
\hline 7 & Miozoa (Dinoflagellata) & 150 \\
\hline 8 & MAGNOLIOPSIDA & 83 \\
\hline 9 & Ochrophyta (Xanthophyta) & 67 \\
\hline 10 & Bryophyta & 59 \\
\hline 11 & Rhodobacteria & 50 \\
\hline 12 & Rhodophyta & 50 \\
\hline 13 & Cryptophyta & 42 \\
\hline 14 & Choanozoa (Protozoa) & 33 \\
\hline 15 & Chlorobacteria & 31 \\
\hline 16 & Bigyra & 19 \\
\hline 17 & Proteobacteria & 14 \\
\hline 18 & Protozoa incertae sedis & 11 \\
\hline 19 & Protozoa (Amoebozoa) & 9 \\
\hline 20 & Metamonada (Protozoa) & 8 \\
\hline 21 & Haptophyta & 6 \\
\hline 22 & POLYPODIOPHYTA & 6 \\
\hline 23 & Ochrophyta (Raphydophyta) & 5 \\
\hline 24 & Katablepharidophyta & 4 \\
\hline 25 & Percolozoa (Protozoa) & 2 \\
\hline 26 & Chlorobia & \\
\hline 27 & Sarcomastigophora (Protozoa) & 2 \\
\hline 28 & Protozoa & Eukaryota unassigned phylum \\
\hline 29 & & \\
\hline & & \\
\hline
\end{tabular}




\begin{tabular}{|l|l|l|}
\hline 30 & Free-living heterotrophic flagellates & 1 \\
\hline 31 & Craspedophyta & 1 \\
\hline 32 & Ascomycota & 1 \\
\hline 33 & Ochrophyta incertae sedis & 1 \\
\hline 34 & Cercozoa (Sponges) & 1 \\
\hline 35 & Pteridophyta & 1 \\
\hline 36 & Glaucophyta & 1 \\
\hline & Total & $\mathbf{8 4 7 5}$ \\
\hline
\end{tabular}

The main database is organized for convenience of orientation in the table with key fields as the unique rows' number. Italic texts denote codes and names of taxa according to the major taxonomic summaries with the additions from a number of articles, books, and electronic resources, as mentioned in the bibliography column. The information in the table on ecological preferences not only includes algae and cyanobacteria but also other groups of organisms inhabiting the water or in areas near the water. Each group of indicators can be separately assessed according to its significance for bioindication. Species that respond predictably to these variables can be used as bioindicators, reflecting the reactions of aquatic ecosystems to eutrophication, $\mathrm{pH}$ levels (acidifications), salinity, and organic pollutants (Porter, 2008). In our current study, this database was used for ecological analysis for many waterbodies, rivers, and lakes of Eurasia.

\section{Conclusion}

The World Bioindicators Database that we compiled with the help of international monographs and our research data currently includes 8475 indicator species. Revealed species are presented in 12 indicator groups, which are from 39 higher aquatic taxa. A complete table of indicators with detailed descriptions of methods and diverse examples of application is planned for publication in 2017 as a book.

A database was compiled for the purpose of pollution impact assessment on fresh and brackish water ecosystems and was implemented in our research (Barinova, 2011) and many other indicators were used for ecological evaluation (Barinova \& Krassilov, 2012) of water quality in aquatic habitats.

Information from our database can be used by a wide spectrum of ecologists in determining aquatic ecosystem assessment and in monitoring water quality levels with the help of bioindication methods.

\section{Acknowledgement}

This work was partly funded by the Israeli Ministry of Absorption. 


\section{References}

Barinova, S. (2011). Algal diversity dynamics, ecological assessment, and monitoring in the river ecosystems of the eastern Mediterranean. New York: Nova Science Publishers, USA.

Barinova, S. S., Medvedeva, L. A., Anissimova, O. V. (2006). Diversity of algal indicators in environmental assessment. Tel Aviv: Pilies Studio (In Russian).

Barinova, S., Krassilov, V. A. (2012). Algal diversity and bio-indication of water resources in Israel. International Journal of Environment and Resource, 1(2), 62-72.

Guiry, M. D., Guiry, G. M. (2017). AlgaeBase. World-wide electronic publication, National University of Ireland, Galway. [Online] Available: http://www.algaebase.org (February 8, 2017).

Porter, S. D. (2008). Algal Atributes: An autecological classification of algal taxa collected by the National Water-Quality Assessment Program. Geological Surevy Data Series, 329. [Online] Available: http://pubs.usgs.gov/ds/ds329/2008.

UNEP/IPCS. Training Module No. 3. Section C, Ecological Risk Assessment, Prepared by The Edinburgh Centre for Toxicology. [Online] Available: http://www.chem.unep.ch/irptc/Publications/riskasse/C2text.pdf, 2006.

Whitton, B. A. (1975). Algae. In: Whitton B. A. (ed.), River Ecology, Oxford: Blackwell Sci. Publ., pp. 81-105.

\section{Copyright Disclaimer}

Copyright for this article is retained by the authors, with first publication rights granted to the journal.

This is an open-access article distributed under the terms and conditions of the Creative Commons Attribution license (http://creativecommons.org/licenses/by/3.0/). 